\title{
Review of Veletsianos, G. (2020) Learning Online: The student experience. Johns Hopkins University Press
}

\author{
Orna Farrell ${ }^{1}$
}

Published online: 6 February 2021

(C) Association for Educational Communications \& Technology 2021

\section{Introduction}

The Covid-19 Pandemic has been a game changer for online education, impacting 1.5 billion students worldwide and thrusting the majority of schooling and higher education online (Bozkurt and et al. 2020). Within this pandemic remote learning context, Veletsianos (2020) Learning Online: The student experience is a timely publication, which considers many of the key debates, theories and approaches in online education from the student perspective. Furthermore, the book has been published open access (https://muse.jhu.edu/book/ 73824), providing a valuable resource to a broad audience including instructors, researchers, instructional designers, administrators.

The aim of the book is to highlight the online student voice, although there has been a huge growth in online learning, very little is known about the lived experiences of online learners. As Veletsianos argues "people involved in HE need to better understand the needs and experiences of students" (Veletsianos 2020, p.2). Furthermore, the qualitative methodology adopted by the author is an intentional antidote to the rise in the datafaction of the student experience.

Drawing on a wide range of student voices and experiences and discussing key topics such as student success, digital literacy, motivation, and artificial intelligence, this book is a good resource for those seeking to better understand how to make online learning a meaningful and successful experience for their students.

\section{Organization}

The introductory chapter of Learning Online: The student experience sets out the focus and approach of the book. By

Orna Farrell

orna.farrell@dcu.ie

1 Dublin City University, Dublin, Ireland learning "more about our students...we can refine and improve online teaching, learning and education" (Veletsianos 2020, p.3). The book is structured into seventeen chapters, each chapter starts with a learner story, then the learner story is analysed and connected to the wider literature and theory. The learner stories are composites drawn from the authors research and published reports. These first person narratives bring a personal and vibrant tone to the chapters and anchor theoretical concepts firmly in the perspective of the student.

\section{Content Overview}

This section gives an overview of the seventeen chapters in Learning Online: The student experience.

The first chapter tackles one of the most divisive debates in online education, the comparison between online versus faceto-face and which is better? Veletsianos argues that this dichotomy is unhelpful and simplistic, characterising face to face as good and online as inherently bad. He concludes that the quality of a course is determined by its design rather than the mode of delivery. Chapter two examines the profiles of online learners as non-traditional. Then, chapter three considers motivation and lifelong learning, followed by a consideration of online student success and attrition in chapter four.

In chapter five, we are introduced to Mark who lives in Panama and shares the only family computer with a poor internet connection with his daughter to study. Mark's story highlights the issue of the digital divide and the importance of access to devices and reliable internet for successful study. Through Mark's story, Veletsianos dispels one of the myths of MOOCS, that "greater access to online learning has not eliminated inequities...it might even exacerbate them" (Veletsianos 2020, p.56). Then, chapter six considers how digital literacy is essential to successful online study. Chapter seven, considers the persistence of isolation and loneliness as a feature of online learning, and how it can be counteracted by presence, community and support. The role of emotions in learning online is considered in chapter eight, 
Veletsianos argues that courses should be designed with care and humanity at their core.

One chapter that stood out for me, was chapter nine. Angie is introverted and chose not to participate in the collaborative activities in the online course she was taking. Instead she would watch the videos and read her fellow classmates posts on the discussion forums. Angie was on track to successfully complete the course. Through Angie's story, we are introduced to students engaging in a peripheral or passive manner in online courses, sometimes negatively referred to as lurking. Veletsianos highlights that peripheral engagement is not necessarily negative behaviour but a different way to engage.

The challenges and concerns prevalent in higher education about cheating and academic integrity are dealt with in chapter ten. Followed by in chapter eleven an examination of another hot topic in higher education: artificial intelligence (AI). Veletsianos considers the debate about whether teachers will be replaced by AI or robots in the future. He thinks that AI could complement online instruction and free teachers up to deal with more high value interactions with students.

Chapters twelve, thirteen and fourteen look at the topics of study skills, social networking and self-directed learning in online education. Massive open online courses (MOOCS) and the open education movement are critically discussed in chapter fifteen. Veletsianos challenges one of the foundational ideas of the open education movement, that MOOCS would democratize education. He argues that without basics like the internet, computers and leisure time disadvantaged groups can't engage with MOOCs.

The penultimate chapter, discusses the need to provide more flexibility in higher education programmes, to enable those with work and/or caring responsibilities to engage in lifelong learning. The final chapter considers the online learner of the future. Veletsianos urges the reader to adopt a critical mindset and to be suspicious of wild predictions about the future of online education. The book concludes with a call to action for those involved in higher education, to consider the student perspective when making decisions about teaching and learning.

\section{Conclusion}

Overall, Veletsianos (2020) Learning Online: The student experience provides a useful overview of key topics and debates in online education from the student perspective. The book would be an excellent primer for those new to the area of online learning. However for those familiar with the area of online education, Learning Online: The student experience covers familiar ground, rather than offering new ideas. The qualitative methodology using learner stories to springboard wider discussion was refreshing and illustrative, however some of the stories felt artificial. To conclude, this book is a good resource for a broad audience, in particular those getting to grips with online education due to the Covid-19 pandemic.

\section{References}

Bozkurt, A., et al. (2020). A global outlook to the interruption of education due to COVID-19 pandemic: Navigating in a time of uncertainty and crisis. Asian Journal of Distance Education, 15(1), 1-126. https://doi.org/10.5281/zenodo.3878572.

Veletsianos, G. (2020). Learning online: The student experience. Baltimore: Johns Hopkins University Press.

Publisher's NotePublisher's Note Springer Nature remains neutral with regard to jurisdictional claims in published maps and institutional affiliations. 